\title{
Descrição da evolução do comportamento motor aquático: um estudo observacional
}

\author{
Description of the aquatic motor behavior evolution: \\ an observational study
}

\begin{abstract}
Rossane Trindade Wizer, ${ }^{1}$ Nadia Cristina Valentini, ${ }^{1}$ Flávio Antônio de Souza Castro. ${ }^{1}$ 'Escola de Educação Física (ESEF), Universidade Federal do Rio Grande do Sul (UFRGS), Porto Alegre, RS, Brasil.
\end{abstract}

Recebido em: abril 2015 / Aceito em: abril 2015

rossanew@hotmail.com

\section{RESUMO}

Objetivo: descrever a evolução do comportamento motor aquático, bem como as características socioafetivas, que crianças iniciantes em um programa de natação apresentam ao longo das primeiras semanas de aprendizagem. Método: foram realizadas observações de 10 crianças, por um período de 12 semanas, ao longo de seis aulas. As observações ocorreram individualmente, durante os 45 minutos de aula. Relatórios descritivos foram realizados a cada observação. Analisaram-se: posição do corpo e da cabeça; ação de pernas e braços; sincronização dos movimentos e movimentos respiratórios. Resultados: todos os participantes melhoraram ou mantiveram a posição do corpo ao longo das observações, resultado que se repetiu quanto à posição da cabeça e também quanto ao movimento das pernas, com exceção de um aluno. Já em relação ao movimento de braços, sincronização dos movimentos e respiração, poucos melhoraram ao longo das observações. Identificou-se também que os aspectos socioafetivos do desenvolvimento interferem sobremaneira na aquisição dessas habilidades. Considerações finais: a pesquisa mostrou que cada indivíduo possui um processo singular de desenvolvimento das habilidades aquáticas. Entretanto, características comuns nesse processo foram identificadas.

Palavras-chave: Desenvolvimento; Habilidades Aquáticas; Criança.

\section{ABSTRACT}

Objective: this study aimed to describe the evolution of aquatic motor behavior, as well as the socio-affective characteristics that beginning children of a swimming program show over the first weeks of learning. Method: 10 children were observed for 12 weeks; six classes were performed. The observations were individual, during all the 45 min of the class. Descriptive reports were carried out at each observation. Body and head position, legs and arms actions, movements' synchronization and respiratory movements were analyzed. Results: all participants improved or maintained the body and head position along the observations, as well as the legs movement, except for one participant. Regarding the arms movement, movement synchronization and breathing, few participants have improved over the study. Socio-affective aspects of development were also identified as large interferents in acquiring these skills. Final considerations: this research has shown that each individual has an unique process of aquatic skills development. However, common features in this process were identified.

Keywords: Development; Aquatic Skills; Child.

\section{INTRODUÇÃO}

O desenvolvimento motor é percebido como um processo não-linear e auto-organizado, o que tem provocado modificações importantes a respeito da forma como se vê o desenvolvimento de diversas habilidades motoras $^{1-3}$, inclusive as aquáticas. Nesta visão, a coordenação não emerge de prescrições para a ação, mas sim como consequência das restrições impostas à ação, indicando a natureza probabilística do processo de desenvolvimento motor ${ }^{1,2}$.

No âmbito das habilidades aquáticas, algumas pesquisas $^{4,5}$ foram realizadas com o propósito de estudar o comportamento motor aquático, sendo que a preocupação básica tem sido identificar sequências de 
desenvolvimento ${ }^{4}$. Para tais sequências, em todos os domínios do desenvolvimento, as mudanças ocorrem de modo similar para diferentes indivíduos ${ }^{5}$. No entanto, são as restrições do organismo, do ambiente e da tarefa, quando integradas, que geram alterações no decorrer do desenvolvimento, e a consideração desses contextos pode levar, até mesmo, a alterações na sequência de desenvolvimento motor ${ }^{1}$.

Pesquisas nessa área têm centrado seus esforcos em descobrir causas e alternativas para evitar o grande número de casos de afogamento infantil ${ }^{6}$, além de investigar a relação dos níveis de habilidades aquáticas com os índices de afogamento ${ }^{7}$. E ainda, outras também vêm sendo feitas com o objetivo de melhor estruturar a prática e otimizar o processo de aprendizagem das habilidades aquáticas ${ }^{8-11}$. Os resultados, até então, ainda são pouco conclusivos e isso aponta para a necessidade de mais estudos sobre o desenvolvimento das habilidades aquáticas.

Um componente essencial no desenvolvimento motor aquático da criança é o comportamento socioafetivo. Por ser o meio aquático um ambiente novo e muitas vezes desconhecido, o medo é um elemento que frequentemente está presente e, por isso, a superação do medo é, até mesmo, prioritária em relação a outros objetivos deste processo ${ }^{12}$. Dessa forma, fica evidente a importância do desenvolvimento socioafetivo para o desenvolvimento das habilidades aquáticas.

O desenvolvimento socioafetivo poderá ser me Ihor aprimorado se a metodologia lúdica for adotada para o ensino das habilidades aquáticas ${ }^{13}$, desviando a importância exagerada dada à técnica para um ensino que privilegie a qualidade das sensações sentidas pelas crianças na água. Percebe-se a necessidade de rever metodologias utilizadas no ensino da natação quando o descontentamento com aulas monótonas e repetitivas aparecem como uma das principais razões do abandono das aulas de natação por parte dos alunos ${ }^{13}$.

Assim, o objetivo desse estudo é descrever a evolução do comportamento motor aquático, bem como as características socioafetivas que crianças iniciantes em um programa de adaptação ao meio líquido apresentam ao longo das primeiras semanas de aprendizagem, buscando apontar similaridades e diferenças nesse processo.

\section{MATERIAIS E MÉTODOS}

Considera-se este estudo descritivo de desenvolvimento, pois descreve a evolução de variáveis durante determinado período ${ }^{14}$. Participaram deste estudo 10 crianças, alunos de escolas de natação de Porto Alegre -RS, com idades entre três anos e três anos e seis meses no início das observações. Nenhuma das crianças no momento de início desta pesquisa, tinha participado de processo formal de aquisição de habilidades aquáticas (adaptação ao meio aquático/aulas de natação). O consentimento informado foi entregue aos pais das crianças assim que os mesmos demonstraram interesse em participar da pesquisa, após a explicação de como seria efetuado o estudo. Este estudo foi aprovado por Comitê de Ética em Pesquisa da Universidade onde foi realizado (parecer número 19686).

Cada criança foi acompanhada por um período de
12 semanas, ao longo de seis aulas, já que as observações foram realizadas a cada duas aulas. As observações ocorreram individualmente, ou seja, a professora pesquisadora observou e descreveu o comportamento motor aquático de apenas um aluno em cada observação, durante os 45 minutos de aula. Foram realizados relatórios descritivos de cada criança a cada observação realizada. Durante as coletas, também eram realizadas anotações referentes ao comportamento motor aquático e socioafetivo da criança e, ao terminar, o pesquisador transcrevia suas anotações e ainda complementava-as com informações que considerasse importantes para a pesquisa.

Três professores (dois do sexo feminino e um do sexo masculino) foram os responsáveis pelas aulas. As piscinas onde as aulas foram observadas eram fundas e nenhuma das criancas conseguia tocar os pés no fundo sem submergir totalmente a face; assim, flutuadores nos braços foram utilizados durante a maior parte das aulas ao longo das observações. Os três professores desenvolviam atividades lúdicas em suas aulas, isso porque proporcionavam atividades recreativas e estimulavam a imaginação das crianças. De modo geral, as atividades consistiam em imitar animais marinhos, utilizar materiais auxiliares à flutuação como "navio", buscar "tesouros" no fundo da piscina. Os professores demonstravam a atividade e pediam que os alunos os acompanhassem. Em nenhum momento foi observado ênfase no aprendizado das técnicas dos nados.

O comportamento motor aquático foi observado a partir de seis categorias ${ }^{15,16}$. Cada categoria possui diferentes possibilidades de análise, a saber:

(1) posição do corpo: vertical, inclinado, horizontal (2)posição da cabeça: alta (vertical), média (inclinada), baixa (horizontal);

(3) ação das pernas: padrão de flexão de quadril e joelhos, padrão de extensão de quadril e joelhos;

(4) ação dos braços: sem movimentos, crawl orientado (braçada de crawl com auxílio do professor), espontâneos (cachorrinho e mergulho), crawl rudimentar;

(5) sincronização dos movimentos de pernas e braços: com ou sem sincronização;

(6) realização dos movimentos respiratórios: não realiza expiração na água, realiza esporadicamente, realiza expiração na água.

Também foram observadas e consideradas para análise, as características referentes ao comportamento socioafetivo apresentado pela criança, frente às primeiras experiências em meio líquido. Compõem essas características a satisfação com a atividade, nível de insegurança, motivação, nível de interesse. A análise das informações foi realizada de forma descritiva, e para manter a identidade das crianças em sigilo, optou-se por referir-se a cada uma delas por letras do alfabeto na ordem em que elas foram observadas. Ou seja, a primeira criança observada foi chamada de aluno $A$, a segunda foi chamada de $B$ e assim, sucessivamente.

\section{RESULTADOS}

Os resultados, em relação à evolução de cada criança, são descritos de modo individual e resumidos na Tabela 1. Para o melhor entendimento do processo de desenvolvimento aquático serão apontadas algumas 
características apresentadas pelas crianças em relação aos aspectos socioafetivos, bem como algumas considerações referentes aos aspectos motores do indivíduo.

Aluno A - Demonstrava insegurança e ansiedade em relação ao meio líquido. A insegurança foi sendo vencida ao longo das aulas. Apresentava descontrole na inspiração e expiração do ar em alguns momentos da aula até o final das observações. No final do período de observações o aluno já mergulhava todo o rosto na água.

Aluno B - Aluno extremamente inseguro. Não mergulhava voluntariamente e quando mergulhado pela mãe demonstrava insatisfação. Movimento de pernas pouco frequente. Até a segunda aula apresentava variabilidade de padrões para o movimento de pernas; a partir da terceira aula, manteve certa regularidade.

Aluno C - Aluno encaminhado à natação por motivo de recuperação de uma fratura no fêmur. Demonstrava insegurança no início das observações, que foi amenizada no decorrer das aulas. Realizava mergulhos voluntários de curta duração.

Aluno D - Aluno tinha contato frequente com ambientes aquáticos. Deslocava-se por longas distâncias em posição horizontal sem auxílio, parando apenas para respirar. Gostava de explorar o meio líquido do seu jeito, resistindo em realizar atividades propostas pela professora. O aumento da frequência tornava o batimento de pernas mais eficiente.

Aluno E - A aluna demonstrava ansiedade em relação ao meio líquido. Realizava mergulhos voluntários de curta duração; no entanto, engolia água em alguns momentos. Quando movimentava as pernas, movimentava o corpo inteiro, como se as articulações funcionassem em bloco.

Aluno $\mathbf{F}$ - A aluna demonstrava insegurança no meio líquido. Expirava o ar, mergulhando apenas a boca na água. Variava muito o padrão de movimento das pernas até a terceira observação.

Aluno G - Demonstrava tranquilidade no meio líquido. Realizava mergulhos voluntários com bloqueio respiratório, expirando o ar na água apenas quando lembrada pelo professor. Apresentava variabilidade nos padrões de movimento de pernas até a terceira observação. A partir da quarta aula, aumentou a frequência de batimentos, o que fez alterar seu padrão, diminuindo a eficiência do movimento.

Aluno H - Apresentava boa relação com o meio líquido. Mergulhava voluntariamente por curtos períodos. Padrão de movimento de pernas modificou-se constantemente. O movimento de pernas, quando executado de maneira lenta, parecia mais relaxado e consistente, o que aumentava a eficiência da ação.

Aluno I - Aluno tinha contato frequente com ambientes aquáticos e demonstrava tranquilidade em relação ao ambiente. Realizava mergulhos voluntários desde a primeira aula, no entanto, com bloqueio respiratório. Para expirar o ar na água precisava ser lembrado pelo professor. O movimento de pernas era eficiente.

Aluno $\mathbf{J}$ - O aluno apresentava receio em relação ao meio líquido. Para mergulhar, encostava apenas parte do rosto na água, expirando o ar pela boca. A partir da terceira aula, apresentou maior tranquilidade em relação ao meio.

\section{DISCUSSÃO}

Buscou-se, no presente estudo, descrever a evolução do comportamento motor aquático, bem como o comportamento socioafetivo no período inicial de aquisição das habilidades aquáticas, procurando, principalmente, apontar características que possam ser consideradas comuns e distintivas nesse processo. De maneira geral, a relação estabelecida entre o conjunto de restrições apresentado por cada indivíduo desencadeou um processo singular de desenvolvimento das habilidades aquáticas. Apesar de ser um processo singular, com olhar atento é possível identificar semeIhanças nos processos de desenvolvimento observados.

A tendência em manter as articulações flexionadas, ou seja, próximas da linha média do corpo, pareceu ser uma característica comum no início do processo de evolução do comportamento motor aquático. Crianças que se sentiam inseguras em relação ao meio apresentaram movimento de pernas e braços com flexão de cotovelos e joelhos por tempo maior. Sobre isso é importante retomar o princípio de direção desenvolvimentista, em que o desenvolvimento de todas as habilidades motoras segue a direção da cabeça aos pés (céfalo-caudal) e do centro do corpo em direção às extremidades (próximo-distal) ${ }^{17}$. Assim, no início da aprendizagem de qualquer habilidade motora, o indivíduo tende a controlar primeiramente o tronco e, posteriormente, as extremidades do corpo. Ocorre que o indivíduo inexperiente tende a congelar graus de liberdade da ação a fim de reduzir os problemas a serem resolvidos ${ }^{18}$. Com a prática, há diminuição na relação de dependência entre as articulações seguindo a direção próximo-distal e também, aumento no controle da força gerada. Talvez, por isso, as crianças do estudo tenham apresentado flexão

Tabela 1 - Avaliação de cada item ao início (pré) e ao final (pós) do período de observação; $n=10$.

\begin{tabular}{|c|c|c|c|c|c|c|c|c|c|c|c|c|}
\hline \multirow[b]{2}{*}{ Criança } & \multicolumn{2}{|c|}{ Corpo } & \multicolumn{2}{|c|}{ Cabeça } & \multicolumn{2}{|c|}{ Pernas } & \multicolumn{2}{|c|}{ Braços } & \multicolumn{2}{|c|}{ Sincronização } & \multicolumn{2}{|c|}{ Respiração } \\
\hline & Pré & Pós & Pré & Pós & Pré & Pós & Pré & Pós & Pré & Pós & Pré & Pós \\
\hline A & vert & incl & alta & me & fle & fle & esp & esp & sem & sem & espor & espor \\
\hline B & incl & incl & alta & alta & fle & fle & sem & sem & sem & sem & espor & espor \\
\hline C & incl & hor & alta & me & ext & fle/ext & sem & sem & sem & sem & espor & $\operatorname{sim}$ \\
\hline D & hor & hor & bai & bai & ext/fle & ext/fle & esp/crud & crud & sem & com & $\operatorname{sim}$ & $\operatorname{sim}$ \\
\hline$E$ & vert & vert & alta & alta & fle & fle & sem & esp. & sem & com & espor & espor \\
\hline $\mathrm{F}$ & vert & incl & alta & alta & fle & fle & sem & esp & sem & sem & não & espor \\
\hline G & incl & incl & me & me & fle/ext & fle/ext & esp & crrud & sem & com & não & espor \\
\hline $\mathrm{H}$ & vert/incl & incl/ho & alta/me & alta/me & fle & fle/ext & sem & sem & sem & sem & espor & $\operatorname{sim}$ \\
\hline I & hor & hor & me/bai & bai & ext & ext & corien & crud & sem & com & não & espor \\
\hline J & vert & vert & alta & alta & fle & fle & sem & esp & sem & com & espor & espor \\
\hline
\end{tabular}

Posição do corpo - vert: vertical; incl: inclinado; hor: horizontal. Posição da cabeça - me: média; bai: baixa. Ação das pernas - fle: flexão; ext: extensão. Ação dos braços - corien: crawl orientado; esp: espontâneo; crud: crawl rudimentar. Controle repiratório - não: não realiza expiração na água; esporad: realiza esporadicamente; sim: realiza expiração na água. 
dos membros inferiores, como um todo, com limitada diferenciação entre as articulações.

No entanto, considera-se importante salientar o processo de desenvolvimento motor aquático do aluno C. Este aluno foi encaminhado à natação por motivos terapêuticos, isso porque foi submetido à imobilização do membro inferior esquerdo por 45 dias devido a uma fratura do fêmur. Nas primeiras duas observações, o aluno apresentou movimentos estendidos nas articulações das pernas; a partir da terceira observação, seus movimentos tornaram-se mais flexionados. Com isso, é possível afirmar que o conjunto de restrições apresentado por essa criança variou consideravelmente das restrições apresentadas pelas demais crianças. Isso nos mostra o quanto alterações no conjunto de restrições são capazes de influenciar, sobremaneira, o desenvolvimento motor do indivíduo ${ }^{1}$.

Embora apenas o membro inferior esquerdo tenha sido privado dos movimentos durante 45 dias, o padrão de movimento apresentado por esse aluno foi alterado em ambos os membros inferiores. A adaptação dos movimentos do lado esquerdo, necessária à recuperação da lesão, gerou modificações também nos movimentos do lado direito, isso porque o padrão rítmico da pernada é um componente altamente estável no repertório motor dos seres humanos ${ }^{19}$. O arranjo motor encontrado pelo aluno C é decorrente das possibilidades dinâmicas do sistema nervoso e de sistemas periféricos em harmonia com as demandas ambientais e da tarefa. Embora haja diversidade e singularidades nas escolhas e buscas por soluções coordenativas, elas são reguladas na direção da eficiência e adaptação ${ }^{20}$.

O tipo de material utilizado como apoio, bem como diferenças nas atividades propostas no ritmo de movimento, também geraram alterações no padrão de movimento utilizado pelas crianças. Sobre isso, observou-se que as crianças possuíam um vasto repertório de padrões motores como sugestão para o problema referente à pernada. Por exemplo, quando as crianças utilizavam o "espaguete" como suporte, seus movimentos se constituíam, na maioria das vezes, de flexões e extensões exageradas nas articulações dos joelhos e quadril. Porém, quando o professor auxiliava as crianças, os movimentos de flexão e extensão das articulações do quadril e dos joelhos tornavam-se mais moderados. Essas mudanças proporcionaram também alterações na posição corporal dos indivíduos. Ao fazer uso do "espaguete", as crianças apresentaram posição corporal de vertical à inclinada, diferentemente de quando eram auxiliadas pelos professores; nesse caso, apresentaram posição corporal de inclinada à horizontal. Isso mostra o quanto a variação de estímulos é importante para desestabilizar os aprendizes e encaminhá-los a um novo padrão de movimento, mais desenvolvido e eficiente.

Faz-se importante ressaltar que os estímulos, quando em interação com o indivíduo, provocam respostas diferentes em relação aos movimentos. Por exemplo, a aceleração do movimento de pernas provocou alterações positivas na resposta da pernada do aluno $D$, que, com o aumento da frequência, apresentava padrões de movimento mais desenvolvido que aqueles já apresentados. Já para as alunas $\mathrm{G}$ e H, a aceleração do movimento desencadeou resposta contrária, ou seja, elas passaram a apresentar padrões de movimento menos desenvolvidos que os anteriormente demonstrados.
Notou-se também que o auxílio do professor facilitou a percepção da criança em relação à posição do seu corpo na água. Ao dar suporte à criança durante os deslocamentos, o professor ofereceu maior segurança, e com isso possibilitou que a criança despendesse maior atenção ao próprio corpo e movimentos, assegurando que as sensações proporcionadas pela água fossem melhor percebidas. O aprendizado dos movimentos específicos do meio aquático depende da compreensão da atuação das forças existentes no meio líquido, logo, possibilitar diferentes formas de sustentação na água, bem como em diferentes posições do corpo, deve facilitar o processo de aprendizagem ${ }^{21}$.

Alunos iniciantes apresentam dificuldades para ajustar os seus comportamentos de acordo com a demanda da tarefa e do ambiente, e isso talvez justifique a grande variabilidade de padrões encontrados ${ }^{22}$. 0 ganho de consistência na ação reflete um processo gradual de definição do plano motor $^{23}$. Inicialmente, a criança não sabe exatamente como realizar a tarefa, por isso seu comportamento é muito inconsistente. Gradativamente, ela descobre a solução motora mais apropriada e, assim, busca sempre repetir o mesmo padrão de movimento, levando-a a menor variabilidade comportamental. Estas considerações são claramente evidenciadas na evolução do comportamento motor aquático dos alunos B, F e G. Esses alunos apresentaram maior variabilidade de padrões em relação ao movimento de pernas até a terceira aula observada; a partir desse período, seus movimentos tornaram-se, gradativamente mais consistentes.

A variabilidade de padrões está fortemente relacionada à mudança ${ }^{2}$ e, em relação a essa afirmação, observou-se que a maioria das crianças estava em um estágio de desenvolvimento favorável à aprendizagem. Os alunos D e I não pareceram muito suscetíveis às mudanças de padrão, por já terem encontrado uma alternativa relativamente eficiente de deslocamento no meio líquido, nesse caso, necessitavam de estímulos mais desafiadores.

Os alunos A, B, C, E, F, J demonstraram insegurança em relação ao meio líquido. Isso ficou evidente a partir dos registros da observação, nos quais foi relatado o desconforto dessas crianças ao contato da água no rosto e os pedidos insistentes para não serem mergulhadas. Além disso, identificou-se resistência pelas mesmas em executar as atividades. Em função da recorrência de situações como essa no ambiente de aprendizagem das habilidades aquáticas, progressos no aspecto afetivo-social são prioritários em relação aos progressos motores ${ }^{12}$

Supõe-se que a insegurança proporcionada pela água seja a causa por trás da posição alta da cabeça que essas crianças adotaram em quase todas as observações realizadas. O posicionamento alto da cabeça pode ter sido uma estratégia para afastar o rosto da água, o que acabou por desencadear posição corporal inclinada ou vertical em relação à superfície, tornando qualquer forma de deslocamento pouco eficiente. As mesmas crianças, com exceção do aluno C (já descrito anteriormente), apresentaram também movimentos flexionados das articulações. A posição elevada da cabeça em relação à superfície da água e a flexão das articulações são consideradas características constitutivas de estágios iniciais do desenvolvimento das habilidades aquáticas ${ }^{15,24}$.

Dessa forma, a posição corporal assumida na água 
parece estar relacionada, também, à autoconfiança em relação ao meio líquido. Para exemplificar, utiliza-se o caso das crianças $\mathrm{D}$ e I, que apresentavam maior tranquilidade $\mathrm{e}$ segurança em relação ao meio líquido, demonstrando posição horizontal do corpo desde o início das observações. Esses aspectos permitem refletir sobre a importância de desenvolver não só os aspectos motores do indivíduo, como também seus aspectos emocionais ${ }^{25}$. Por exemplo, ao adquirir confiança na água, a posição da cabeça é alterada com facilidade, já que não existirá mais a resistência da criança em evitar o contato da água no rosto. Com isso, o corpo também assume posição adequada para o deslocamento eficiente na água.

É importante salientar que as primeiras aulas de natação devem ser utilizadas para familiarizar as crianças com o meio líquido ${ }^{8,23,25}$. A familiarização com o meio proporciona, aos poucos, melhora na autoconfiança e diminuição da ansiedade, bem como o relaxamento dos músculos; com isso, o corpo assume posição menos vertical em relação à superfície. Isso ocorreu com os alunos A, C, F e H, que melhoraram a posição da cabeça e do corpo ao longo das aulas. Resultados de pesquisa mostraram que o grau de ansiedade relacionado ao meio líquido influencia no desempenho aquático da criança ${ }^{26}$.

De acordo com as descrições obtidas nas observações, as crianças apresentaram poucas alterações em relação à posição da articulação do tornozelo. A maioria delas apresentou flexão plantar, sem alterar a posição dessa articulação durante os deslocamentos. Apenas uma aluna $(F)$ apresentou mudanças de posição nessa articulação, alterando de flexão plantar para flexão dorsal nos momentos que se caracterizavam pela execução de movimentos de bicicleta, ou seja, trajetória circular das pernas, empurrando a água para trás com a planta dos pés. Esse padrão de pernada ocorreu na segunda e na sexta observação. Supõe-se que a ausência de alterações na articulação do tornozelo em quase todas as crianças observadas se deva à consciência corporal ainda em desenvolvimento, pois a habilidade de diferenciar as partes do corpo e organizá-las para um ato motor ainda está em processo de desenvolvimento em crianças de três anos de idade ${ }^{17}$.

Quanto ao movimento de braços, é possível afirmar que o seu aparecimento não ocorreu de forma igualmente espontânea por parte das crianças, como ocorreu com o movimento de pernas. Todas as crianças observadas apresentaram movimento de pernas e ainda, variado repertório de soluções motoras para o problema da pernada, diferentemente do movimento de braços. Mais da metade das crianças não apresentaram qualquer tipo de movimentação dos braços no início das observações e, três delas não apresentaram movimentos espontâneos de braços no término das observações. Padrões de pernada parecem surgir como forma primitiva de movimentação no meio líquido ${ }^{27}$. $\mathrm{O}$ componente braço é incorporado posteriormente em um estilo de nado mais refinado e, culturalmente determinado.

Percebeu-se também que houve uma tentativa, por parte dos professores, de estimular o movimento de circundução alternada da articulação dos ombros com recuperação aérea (roda gigante) através da prática guiada. No entanto, ao direcionar o movimento da criança para um gesto específico em estágios inicias do desenvolvimento, professores estão limitando a exploração livre dos movimentos e impedindo que a criança crie e expresse soluções motoras variadas para deslocar-se no meio líquido. A diversificação de habilidades motoras desempenha um papel muito importante no desenvolvimento motor da criança, isso porque a sua falta caracterizaria uma rigidez de estrutura que dificultaria o aumento de complexidade motora ${ }^{28}$.

Os movimentos exibidos de forma espontânea pelas crianças consistiam, primeiramente, em aproximar e afastar os braços simultaneamente da linha média do corpo (mergulho), e ainda, movimentos curtos e alternados das mãos, embaixo do peito, como se cavasse um buraco (estilo cachorrinho). Sequências de desenvolvimento motor aquático apontam o estilo cachorrinho como o primeiro padrão de desenvolvimento no qual as crianças apresentam algum tipo de movimento espontâneo para deslocarem-se no meio líquido ${ }^{15}$. Apesar disso, a maioria das crianças não apresentou este padrão como forma de solução motora para o deslocamento. E ainda, as crianças que apresentaram o padrão de braçada estilo cachorrinho $(A, G$ e J), apresentaram posição verticalizada na água ou movimentos flexionados do corpo, ou seja, demonstravam estar em estágios iniciais de desenvolvimento, no que se refere à posição corporal, ou no que se refere ao movimento de pernas. As crianças, em geral, apresentaram dificuldades para coordenar o movimento simultâneo de membros inferiores e superiores. Os alunos que o fizeram acabaram por apresentar movimento de pernas em níveis mais elementares de desenvolvimento ao conciliar membros inferiores e superiores concomitantemente. A escolha por um padrão mais rudimentar se deve ao fato de este ser mais estável e de certa forma mais confiável como forma de lidar com as novas demandas ${ }^{16}$.

Quanto aos movimentos respiratórios, é possível supor que o grau de exigência dessa habilidade é muito alto para crianças em nível tão inicial de desenvolvimento, portanto, optou-se por analisar o nível de controle respiratório. Acredita-se que o desenvolvimento dessa habilidade esteja fortemente associado ao nível de ansiedade em relação ao meio líquido. Era tanta a ansiedade gerada pelo novo meio, que os alunos esqueciam de expirar o ar. Supõe-se que o bloqueio respiratório se deva ao foco de atenção dado em demasia aos movimentos ainda no estágio inicial de aprendizagem, já que este se caracteriza por exigir níveis maiores de atenção do aprendiz, que está tentando atender a todas exigências feitas pelo professor ${ }^{29}$. Além disso, o aluno ainda não é capaz de dirigir a atenção apenas aos aspectos relevantes da ação motora, comprometendo a qualidade do movimento.

Para o primeiro nível de aprendizagem das habilidades aquáticas, sugere-se que a adaptação dos órgãos sensoriais e da respiração sejam enfatizados, por serem de primordial importância para a continuação do processo de aprendizagem das habilidades aquáticas $^{25}$. Concomitante com esse conteúdo, sugere-se que sejam trabalhados os aspectos referentes à conquista da confiança para enfrentar os desafios e desenvolver a autonomia. Nota-se que o controle respiratório está ligado também a outros domínios do desenvolvimento e, para aprimorá-lo, deve haver avanços no desenvolvimento global da criança quanto a sua relação com o meio líquido. Dessa forma, é importante respeitar o tempo de aprendizagem de cada criança, proporcionando atividades condizentes a seu nível de desenvolvimento motor, emocional e cognitivo. 
A pesquisa mostrou que cada indivíduo possui um processo singular de desenvolvimento das habilidades aquáticas, no qual cada um apresenta diferentes respostas motoras para os problemas que se apresentam, por exemplo, movimento de pernas e movimento de braços. Dessa forma, torna-se difícil referir-se a uma sequência comum de desenvolvimento motor aquático, em que estágios bem definidos são estabelecidos. Entretanto, características comuns no processo de desenvolvimento das habilidades aquáticas foram observadas. Observou-se, por exemplo, uma tendência nos indivíduos em manter as articulações flexionadas no início do processo de desenvolvimento das habilidades aquáticas. Dessa forma, supõe-se que os padrões de movimento emergem como consequência de restrições impostas à ação e a similaridade de restrições as quais os indivíduos são expostos justificam semeIhanças no desenvolvimento'. Além disso, os resultados do estudo apontam para a necessidade de desenvolver também os aspectos socioafetivos, como superação do medo e confiança, para aprimorar o processo de desenvolvimento das habilidades aquáticas.

\section{REFERÊNCIAS}

1. Newell KM. Constraits on the development of coordination: Motor Development in Children, aspects of coordination and control. Dordrecht: Martinus Nijhoff; 1986.

2. Marques I, Manoel EJ. O processo de desenvolvimento motor visto nas entrelinhas: a instabilidade e transição como referências. Boletim do Laboratório de Comportamento Motor. São Paulo; 2000.

3. Thelen E, Smith L. Handbook of Child Psychology. New Jersey: John Wiley; 2006.

4. Filho EX, Manoel E J. A habilidade nadar e o estudo do comportamento motor. In.: TANI G. (ed.). Comportamento Motor: Aprendizagem e Desenvolvimento. Rio de Janeiro: Guanabara Koogan; 2008. p. 285 - 294.

5. Moreno JA, Perez LMR. Aquatic Perceived Competence in Children: Development and Preliminary Validation of a Pictorial Scale. International Journal of Aquatic Research and Education. 2008; 2: 313-329.

6. Langendorfer S. Considering Drowning, Drowning Prevention, and Learning to Swim. International Journal of Aquatic Research and Education. 2011; 5: 236 - 243.

7. Asher KN, Rivara FP, Felix D, Vance L, Dunne R. Water safety training as a potential means of reducing risk of young children's drowning. Injury Prevention. 1995; 1: 228 - 233.

8. Costa AM, Marinho DA, Rocha $H$, Silva AJ, Barbosa TM, Ferreira SS. Deep and Shallow Water Effects on Developing Preschoolers Aquatic Skills. Journal of Human Kinetics. 2012; 32: 211-219

9. Grosse SJ. Water Learning: Tapping the Educational Potential of Aquatics. International Journal of Aquatic Research and Education. 2011; 5: 42 - 50.

10. Kjendlie PL, Mendritzki M. Movement patterns in free water play after swimming lessons with flotation aids. International Journal of Aquatic Research and Education. 2012; 6: 149 - 155.

11. Michielon G, Scurati R, Roione GC, Invernizzi PL. Analysis and comparison of some aquatic motor behaviors in young children. Revista Portuguesa de Ciências do Desporto. 2006; 6(2): 235-236.

12. Gama RIRB, Carracedo V. Estratégias de ensino do nadar para crianças: o desenvolvimento de aspectos motores, cognitivos e afetivossociais. In: Costa PHL (org.). Natação e atividades aquáticas: subsídios para o ensino. Barueri: Manole; 2010. p. 139-154.

13. Moisés MP. Ensino da natação: expectativas dos pais de alunos. Revista Mackenzie de Educação Física e Esporte. 2006; 5(2): 65-74.

14. Gaya A. Ciências do Movimento Humano: introdução à metodologia da pesquisa. Porto Alegre: Artmed; 2008. Capítulo 11, Desenhos metodológicos V: delineamentos do tipo ex post facto; p. 151-172.

15. Langendorfer SJ, Bruya LD. Aquatic readiness: developing water competence in young children. Champaign, IL: Human Kinetics; 1995.

16. Xavier Filho E. O efeito das restrições da tarefa e do ambiente no comportamento de locomoção no meio aquático. Dissertação (Mestrado). São Paulo: Escola de Educação Física e Esporte, Universidade de São Paulo; 2001.

17. Gallahue DL, Ozmun JC. Compreendendo o desenvolvimento motor: bebês, crianças, adolescentes e adultos. 3. ed. São Paulo: Phorte; 2005.

18. Jensen JL, Thelen E, Ulrich BD, Schneider K, Zernicke RF. Adaptive Dynamics of the Leg Movement Patterns of Human Infants: III. Age-Related Differences in Limb Control. Journal of Motor Behavior. 1995; 27(4): 366-374.

19. Ulrich BD. Development of Stepping Patterns in Human Infants: A Dynamical Systems Perspective. Journal of Motor Behavior. 1989; 21(4): 392-408.

20. Mauerberg-de Castro E. Abordagens teóricas do comportamento motor. Conceitos dinâmicos aplicados aos processos adaptativos e à diversidade do movimento. In: M. G. Guedes (org.). Aprendizagem Motora. Edições FMH. Lisboa. 2001. p. 105-125.

21. Castro FAS, Loss JF. Forças no meio líquido. In: Costa, P. H. L. da. (org). Natação e atividades aquáticas: subsídios para o ensino. Barueri: Manole; 2010. p. 34-46.

22. Langendorfer SJ. Children's movement in water: a developmental and environmental perspective. Children's Environment Quarterly. 1987; 4(29): 25-32.

23. Xavier Filho E, Manoel EJ. Desenvolvimento do comportamento motor aquático: implicações para a pedagogia da Natação. Revista Brasileira de Ciência e Movimento. 2002; 10(2): 85-94.

24. Erbaugh SJ. The development of swimming skills of preschool children over a one and one-half year period. Doctoral dissertation, University of Wisconsin-Madison. Dissertation Abstracts International, 1981.

25. Freudenheim AM, Gama RIRB, Carracedo VA. Fundamentos para elaboração de programas de ensino do nadar para crianças. Revista Mackenzie de Educação Física e Esporte. 2003; 2(2): 61-69.

26. Erbaugh SJ. Effects of body size and body mass on the swimming performance of preschool children. Human Movement Science. 1986; 5: 301-312.

27. Erbaugh SJ. Effects of aquatic training on swimming skill development of preschool children. Perceptual and Motor Skills. 1986; 62: 439-446.

28. Tani G, Basso L, Corrêa UC. O ensino do esporte para crianças e jovens: considerações sobre uma fase do processo de desenvolvimento motor esquecida. Revista Brasileira de Educação Física e Esporte. 2012; 26(2):339-50.

29. Ladewig I. A importância da atenção na aprendizagem de habilidades motoras. Revista Paulista de Educação Física. 2000; 3: 62-71. 